\title{
WHAT YOU SEE IS NOT WHAT YOU GET: SOCIAL SKILL AND IMPULSE CONTROL CAMOUFLAGE MACHIAVELLIANISM
}

\author{
BASTIAN KUECKELHAUS \\ University of Bonn \\ Department of Psychology \\ Industrial, Organizational and Economic Psychology \\ Kaiser-Karl-Ring 9 \\ 53111 Bonn, Germany \\ IRIS KRANEFELD \\ University of Bonn \\ NORA SCHUETTE \\ University of Bonn \\ DOMINIC-NICOLAS GANSEN-AMMANN \\ Hochschule Fresenius University of Applied Sciences Cologne \\ ANDREAS WIHLER \\ Frankfurt School of Finance \& Management \\ GERHARD BLICKLE \\ University of Bonn

\section{INTRODUCTION}

Recent studies found that social skill can transform negative workplace outcomes from dark triad personality traits (narcissism and psychopathy) into positive outcomes (Owens, Wallace, \& Waldman, 2015; Schütte et al., 2018). In the present study, we focus on the third trait of the dark triad: Machiavellianism (MACH). This construct was originally developed as a personality trait by Christie and Geis (1970) on the basis of a selection of statements from the political theory by Niccolò Machiavelli, an Italian writer of the Renaissance period. He argued that politics is amoral and that any means, however unscrupulous, are normal and effective for achieving and retaining political power. At the same time, politicians need to create a positive image to be effective. And indeed, biographic analyses have identified the character trait of MACH in prominent political figures such as John F. Kennedy, Mahatma Gandhi, Fidel Castro, and many other politicians.

Machiavellians can also be found in the workplace (Dahling, Whitaker, \& Levy, 2009) because political perspectives also apply to organizations and careers (Blickle, Frieder, \& Ferris, 2018). For narcissism and psychopathy, social skill engenders the sustainable upside of these traits in organizations (Owens et al., 2015; Schütte et al., 2018). However, for MACH, we argue that social skill creates a protective façade for the long-term successful enactment of its dark core in the workplace. Building on mimicry-deception theory (Jones, 2014), we suggest that some individuals high in $\mathrm{MACH}$ use a complex, long-term deceptive strategy: At first, they create a positive image in order to become well-integrated into the organization. Subsequently, 
interpersonal harm and organizational misbehavior follow. However, the dose of counterproductive work behavior (CWB; Bennett \& Robinson, 2000) in the long run remains at such a well-calculated level that the positive evaluation of these individuals by coworkers concerning career role performance (Welbourne, Johanson, \& Erez, 1998) is not jeopardized. Thus, if the protective façade of the wrongdoers is effective, what coworkers see is not what the host organizations will get in the long run.

\section{THEORETICAL FOUNDATIONS}

Socioanalytic personality theory holds that individuals in social interactions are motivated by a specific combination of two motives: a need for status, power, and the control of resources, and a need for community, approval, and acceptance. These needs are referred to as the motive to get ahead and the motive to get along (Hogan \& Blickle, 2018). Individuals high in MACH tend to have a high motive to get ahead, while the motive to get along is low. In essence, these motives reflect individuals' interpersonal aspirations (i.e., what one aspires to do). However, not everyone who aspires to get along or get ahead is equally equipped to do so. Accordingly, whether individuals are successful at pursuing either or both of these basic motives will depend on their social skill.

Social skill refers to individual differences in how one goes about pursuing their motives. As such, individuals who are socially skilled are more capable of translating their basic social motives (i.e., their aspirations) into purposeful and, more importantly, successful action. Given the widespread evidence establishing a certain kind of social skill, that is, political skill, as an important workplace-specific social competency (e.g., Blickle et al., 2018), Machiavellians with political skill are capable of transforming a desire to get ahead into social success. Without political skill, however, it is likely that individuals high in MACH will engage openly in CWB and this will be followed by a lack of success in getting ahead in organizations. Consequently, from a socioanalytic perspective, the negative image of some individuals high in MACH to have a "preference for politicking instead of paying thorough attention to their duties" (Zettler \& Solga, 2013: 546) merely reflects a lack of political skill. O'Boyle et al. (2012: 559) noted, "A willingness to manipulate does not necessarily coincide with the ability to manipulate". And such a negative image may also reflect a lack of sufficient impulse control.

Individuals high in dysfunctional impulsivity act "“without thinking,' without giving themselves time to assess the situation, to appreciate dangers, to foresee the consequences, or even to anticipate how they will feel about their action themselves when they have time to consider it" (Lykken, 1995: 122). MACH, however, is conceptually thought to include "a longterm, strategic focus, the ability to delay gratification, and average to good impulse control" (Miller et al., 2017: 440). Collison et al. (2018) criticized the insufficient construct coverage of the mainstream measures of MACH (e.g., Mach-IV, MPS, Dirty Dozen; Christie \& Geis, 1970; Dahling et al., 2009; Monaghan et al., 2018; Jonason \& Webster, 2010) because they do not represent this aspect of MACH. The meta-analysis by Monaghan et al. (2018) even reported positive associations between some of these mainstream measures of MACH and impulsivity and negative associations with conscientiousness. Impulse control is especially important in light of mimicry deception theory (Jones, 2014).

Mimicry-Deception Theory (MDT; Jones, 2014) concerns the strategies used to deceive others. Drawing from the behavior of predatory nonhuman animals and parasites, two different strategies are distinguishable: a superficial short-term approach that is susceptible to detection 
but enables the extraction of resources in a short amount of time and a long-term strategy, comparable to a parasitic infection, in which the predator uses more complex deception approach to achieve host integration and slowly extract resources with minimal risk of being detected.

MDT suggests that individuals high in MACH use these two overarching strategies when interacting with others in their organizations. Dahling et al. (2009) found that people high in $\mathrm{MACH}$ with long job tenure obtained elevated task performance ratings. According to MDT, such a finding can be interpreted as an indication of increased integration into the host organization after a longer period of time. Thus, there is empirical evidence supporting the theoretical argument that length of job tenure is critical for the effects of $\mathrm{MACH}$ in the workplace to occur.

\section{HYPOTHESES BUILDING}

$\mathrm{MACH}$ represents the motive to get ahead at the expense of others by manipulating and betraying others when the opportunity for personal advantage or advancement is present. Individuals high in social skill have the ability to engage in complex deception at work. They are able to present themselves as sincere and trustworthy and can successfully use impression management tactics in the workplace. Individuals low in impulse control use little time to assess the situation, they do not anticipate long-term consequences, and they act without forethought and without carefully considering alternative ways to solve problems. Individuals high in impulse control, by contrast, think first and act later, learn from their mistakes, carefully plan ahead, and put a great deal of thought into their long-term goals. Consequently, individuals high in $\mathrm{MACH}$, low in social skill, and low in impulse control will use superficial deception tactics, whereas individuals high in impulse control, high in $\mathrm{MACH}$, and high in social skill will use complex deception tactics with different short- and long-term consequences for CWB and the assessment of career role performance.

Career role performance refers to how well employees progress in their career roles, seek out career opportunities, develop skills needed for future career steps, and obtain personal career goals (Welbourne et al., 1998). Coworkers' assessments of targets' career role performance reflect targets' personal reputations for career success potential in their organization. Ambitious and socially skilled employees aim to create a positive image because personal reputation facilitates career success (Hogan \& Blickle, 2018).

Blickle and Schütte (2017) found that low impulse control is associated with low task performance and high CWB directed toward the organization. In addition, meta-analytic research has reported that political skill is positively associated with job performance, reputation, and career success (Munyon et al., 2015). In the case of $\mathrm{MACH}$, job tenure plays an important role because MDT suggests that the deceptive extraction of resources increases with a longer tenure after individuals high in MACH have built a positive reputation.

Thus, we postulated that the relationship between $\mathrm{MACH}$ and career role performance will be moderated by targets' job tenure, impulse control, and social skill. For short tenure we postulate that employees with low impulse control and low political skill will get lower levels of career role performance assessments by their coworkers than employees with either high impulse control and/or high political skill. Individuals with high levels of MACH will thus be able to hide behind the façade of high impulse control and high political skill.

Secret organizational resource extraction is a form of CWB. CWBs are those discretionary employee behaviors that violate organizational norms, run counter to an 
organization's best interests, and threaten employees' or the organization's well-being (Bennett \& Robinson, 2000). According to MDT, such forms of CWB should increase in individuals high in MACH impulse control, and social skill after they have achieved heavy integration into their organization. In other words, when tenure is short, the incidence of such behaviors should be low, but if tenure is high, the incidence of such behaviors should increase as a function of $\mathrm{MACH}$.

On the basis of MDT with respect to predatory behavior with superficial deception, first, for individuals low in impulse control and social skill, we expect that MACH will positively predict CWB for both short and long tenures. Second, on the basis of MDT and socioanalytic theory with respect to prior façade building as part of a complex long-term deception strategy, we predict that for a short tenure, the level of CWB in individuals high in MACH, social skill, and impulse control will remain low, even for those with high levels of MACH. Third, on the basis of MDT with respect to resource extraction after integration into the organization, we expect that for a long tenure, in individuals with high social skill and impulse control, MACH will positively predict CWB. Finally, on the basis of MDT with respect to slow resource extraction and low risk of detection as part of a complex long-term deception strategy, we expect that even at high levels of $\mathrm{MACH}$, the level of $\mathrm{CWB}$ of individuals high in social skill and impulse control will be lower than the CWB of individuals with other combinations of social skill and impulse control.

\section{METHOD, RESULTS AND DISCUSSION}

\section{Method}

We tested our hypotheses using a triangular multisource design in two complementary workplace samples with overall $N=1,438$ participants. Sample 1 consisted of $N=251$ target employees, who gave self-ratings on $\mathrm{MACH}$, job tenure, social skill, and impulse control as well as two corresponding other-ratings by coworkers, who assessed targets' career role performance. Sample 2 consisted of $N=685$ employees who rated their CWB in addition to MACH, job tenure, social skill, and impulse control.

In both samples MACH was measured using the Machiavellian Personality Scale (Dahling et al., 2009), social skill was measured using the Political Skill Inventory (Lvina et al., 2012), and Job tenure was assessed by asking participants how long they held their current job. To assess impulse control, we combined a measure of conscientiousness with the careful nonplanfulness scale of the PPI-R (Sample 1, Alpers \& Eisenbarth, 2008) and in Sample 2 the disinhibition scale from the TriPM scale (Eisenbarth, Castellino, Alpers, Kirsch \& Flor, 2015). Combining these measures allowed us to assess the whole range of impulse control, ranging from problematic impulsivity to planful control. Targets' career behavior was assessed in Sample 1 by two coworkers each, using the Career Role Behavior Scale (Welbourne et al., 1998) and CWB was based on self-reports by targets in Sample 2, using the Workplace Deviance Scale (Bennett \& Robinson, 2000). The researchers provided garantuee for complete data anonymity.

\section{Results and Discussion}

The results supported our hypotheses. The results of Sample 1 concerning the other-rated career role performance indicated that career role performance assessed by coworkers critically 
depended upon high social skill and impulse control if job tenure was low. Targets high in $\mathrm{MACH}$ received high performance ratings if they also scored high on social skill and impulse control. Thus scoring high in social skill and impulse control effectively masked individuals' high MACH. Regarding individuals with long job tenure, MACH was the functional driver of the career role performance image in coworkers if target individuals also scored high on social skill and impulse control.

In Sample 2, we found that if job tenure was short, individuals high in MACH and high in social skill and impulse control reported low levels of CWB. If tenure was high, individuals high in MACH and high in social skill and impulse control reported exponentially increased levels of CWB. However, the level of CWB in these individuals was still at a moderate level, thereby keeping these target workers inconspicuous while they secretly extracted organizational resources.

In sum, social skill and impulse control effectively masked the dark core of the Machiavellian personality at work while such individuals were able to display a positive image.

\section{CONCLUSION}

With this study, we demonstrate how impulse control and social skill can effectively mask Machiavellianism in the workplace with dire long-term consequence for coworkers and organizations.

\section{REFERENCES}

Alpers, G. W., \& Eisenbarth, H. 2008. PPI-R. Psychopathic Personality Inventory-Revised. German Version. Göttingen: Hogrefe.

Bennett, R. J., \& Robinson, S. L. 2000. Development of a measure of workplace deviance. Journal of Applied Psychology, 85: 349-360.

Blickle, G., Frieder, R., \& Ferris, G. R. 2018. Political skill. In D. S. Ones, N. R. Anderson, C. Viswesvaran, \& H. K. Sinangil (Eds.), The SAGE Handbook of Industrial, Work \& Organizational Psychology: Personnel Psychology and Employee Performance: 299-319. Los Angeles, CA: Sage.

Blickle, G., \& Schütte, N. 2017. Trait psychopathy, task performance, and counterproductive work behavior directed toward the organization. Personality and Individual Differences, 109: 225-231.

Christie, R., \& Geis, F. L. 1970. Studies in Machiavellianism. New York, NY: Academic Press.

Collison, K. L., Vize, C. E., Miller, J. D., \& Lynam, D. R. 2018. Development and preliminary validation of a Five Factor Model measure of Machiavellianism. Psychological Assessment, 30: 1401-1407.

Dahling, J. J., Whitaker, B. G., \& Levy, P. E. 2009. The development and validation of a new Machiavellianism scale. Journal of Management, 35: 219-257. 
Eisenbarth, H., Castellino, N., Alpers, G. W., Kirsch, P., \& Flor, H. 2015. The triarchic model of psychopathy - questionnaire in action: validity and reliability in a German sample. Manuscript in preparation.

Hogan, R. \& Blickle, G. 2018. Socioanalytic Theory: Basic concepts, supporting evidences, and practical implications. In V. Zeigler-Hill, \& T. K. Shackelford (Eds.), The SAGE Handbook of Personality and Individual Differences: 110-129. Thousand Oaks, CA: SAGE.

Jonason, P. K., \& Webster, G. D. 2010. The Dirty Dozen: A concise measure of the dark triad. Psychological Assessment, 22: 430-432.

Jones, D. N. 2014. Predatory personalities as behavioral mimics and parasites: MimicyDeception Theory. Perspective on Psychological Science, 9: 445-451.

Lvina, E., Johns, G., Treadway, D. C., Blickle, G., Liu, Y., Liu, J., Atay, S., Zettler, I., Solga, J., Noethen, D., \& Ferris, G. R. 2012. Measure invariance of the Political Skill Inventory (PSI) across five cultures. International Journal of Cross-Cultural Management, 12: 171-191.

Lykken, D. T.1995. The antisocial personalities. Hillsdale, NJ: Erlbaum.

Miller, J. D., Hyatt, C. S., Maples-Keller, J. L, Carter, N. T., \& Lynam, D. R. 2017. Psychopathy and Machiavellianism: a distinction without a difference. Journal of Personality, 85: 439453.

Monaghan, C., Bizumic, B., \& Sellbom, M. 2018. Nomological network of two-dimensional Machiavellianism. Personality and Individual Differences, 130: 161-173.

O'Boyle Jr., E. H., Forsyth, D. R., Banks, G. C., \& McDaniel, M. A. 2012. A meta-analysis of the dark triad and work behavior: a social exchange perspective. Journal of Applied Psychology, 97: 557-579.

Owens, B. P., Wallace, A. S., \& Waldman, D. A. 2015. Leader narcissism and follower outcomes: the counterbalancing effect of leader humility. Journal of Applied Psychology, 100: $1203-1213$.

Schütte, N., Blickle, G., Frieder, R., Wihler, A., Schnitzler, F., Heupel, J., \& Zettler, I. 2018. \#he role of interpersonal influence in counterbalancing psychopathic personality trait facets at work. Journal of Management, 44: 1338-1368.

Welbourne, T. M., Johnson, D. E., \& Erez, A. 1998. The role-based performance scale: validity analysis of a theory-based measure. Academy of Management Journal, 41: 540-555.

Zettler, I., \& Solga, M. 2013. Not enough of a 'dark' trait? Linking Machiavellianism to job performance. European Journal of Personality, 27: 545-554.\# 